\title{
Estrogen stimulates the invasion of ovarian cancer cells via activation of the PI3K/AKT pathway and regulation of its downstream targets E-cadherin and $\alpha$-actinin-4
}

\author{
ZHIYING LU ${ }^{1,2}$, YING ZHANG $^{1,2}$, XIAOHUI YAN ${ }^{1,2}$, YISONG CHEN $^{1,2}$, XIANG TAO $^{3}$, JIAJIA WANG ${ }^{1,2}$, \\ NAN JIA ${ }^{1,2}$, TIANJIAO LYU ${ }^{1,2}$, JUNYAN WANG ${ }^{1,2}$, JINGXIN DING ${ }^{1,2}$, WEIWEI FENG ${ }^{1,2}$ and KEQIN HUA ${ }^{1,2}$ \\ ${ }^{1}$ Department of Gynecology; ${ }^{2}$ Shanghai Key Laboratory of Female Reproductive Endocrine-Related Diseases; \\ ${ }^{3}$ Department of Pathology, The Obstetrics and Gynecology Hospital, Fudan University, Shanghai 200011, P.R. China
}

Received September 3, 2013; Accepted May 9, 2014

DOI: $10.3892 / \mathrm{mmr} .2014 .2561$

\begin{abstract}
Previous studies by our group revealed that the phosphoinositide 3-kinase (PI3K)/AKT pathway was involved in estrogen-induced metastasis in ovarian cancer cells. In the present study, the role and mechanism of estrogen-induced invasion was further explored using a stable short hairpin RNA (shRNA) estrogen receptor $\alpha / \beta$ (ER $\alpha / \beta)$ SKOV3 cell line when ER $\alpha$ and ER $\beta$ were knocked down by lentiviral infection. The effects of estrogen and LY294002, a PI3K inhibitor, on the invasion of shRNA ER $\alpha / \beta$ SKOV 3 cells were evaluated in vitro and in vivo. 17- $\beta$ estradiol promoted cell invasion, activated phosphorylated AKT in a dose- and time-dependent manner, decreased E-cadherin and increased cytoplasmic $\alpha$-actinin- 4 expression. When the PI3K/AKT pathway was suppressed by LY294002, the effect of estrogen was attenuated. Estrogen stimulated the growth of shRNA ER $\alpha / \beta$ SKOV3 xenograft tumors in nude mice, whereas LY294002 inhibited the growth and antagonized the effect of estrogen. The results indicate that estrogen promotes the invasion of ovarian cancer cells via activation of the PI3K/AKT pathway, downregulation of E-cadherin and upregulation of $\alpha$-actinin- 4 in an ER-independent manner. Inhibiting the PI3K/AKT pathway may be a useful treatment for ovarian carcinoma.
\end{abstract}

\section{Introduction}

Ovarian cancer is the leading cause of mortality from gynecological tumors, primarily due to its aggressive metastasis within the peritoneal cavity. The ovaries are a main source and target organ of estrogen. Increasing evidence suggests that estrogen has an important role in ovarian cancer cell metastasis $(1,2)$.

Correspondence to: Dr Keqin Hua or Dr Weiwei Feng, Department of Gynecology, The Obstetrics and Gynecology Hospital, Fudan University, 419 Fangxie Road, Shanghai 200011, P.R. China

E-mail: huakeqin@126.com

E-mail: jingsakura@gmail.com

Key words: ovarian cancer, estrogen, AKT, invasion, $\alpha$-actinin-4
It has been traditionally understood that estrogen exerts its malignant biological behavior by binding to the nuclear estrogen receptor (ER). However, a previous study conducted by our group found that estrogen stimulated the migration of ovarian cancer cells with a low level of ER expression (1). We further showed that the metastatic effect of estrogen could be mediated by the phosphoinositide 3-kinase (PI3K)/AKT pathway rather than the classical ER pathway $(2,3)$.

PI3K/AKT signal transduction plays a critical role in cell biological behavior in various forms of human cancers, including ovarian carcinoma (4-8). The increased AKT activation or dysregulation due to elevated AKT expression and indirect changes in AKT regulators result in cell metastasis signaling activation. Dozens of downstream substrates of AKT have been identified, including those associated with metastasis in cancer cells, such as nm23-H1 (2), E-cadherin $(9,10)$ and $\alpha$-actinin-4 (11,12). E-cadherin, a tumor suppressor gene, can be regulated by the PI3K/AKT pathway. Decreased expression of E-cadherin is often associated with epithelial mesenchymal transition and metastasis (13-18). $\alpha$-actinin-4 localization is regulated by the PI3K/AKT pathway. The activation of the PI3K/AKT pathway has been suggested to promote the transfer of $\alpha$-actinin- 4 from the nucleus to the cytoplasm and plasma membrane, resulting in alterations in cell morphology and motility. This plays a crucial role in the process of cancer invasion and metastasis $(11,12)$.

In order to elucidate the mechanisms underlying the action of estrogen via the AKT pathway, instead of the classical ER pathway, an ovarian cancer cell line with ER $\alpha$ - and $\beta$-knockdown was established in the present study.

\section{Materials and methods}

Construction of lentiviral vectors. To generate ER $\alpha$ and $\beta$ short hairpin RNA (shRNA)-expressing plasmids, the stuffer DNA was removed from pLKO.1 by AgeI/EcoRI digestion and replaced with double-stranded oligos encoding the desired shRNA and $A g e \mathrm{I} / E c o$ RI sites. The target-specific ER $\alpha$ and $\beta$ shRNA sequences used in the present study were obtained from The MISSION ${ }^{\circledR}$ shRNA library [The RNAInterference Consortium (TRC)/Sigma-Aldrich, St. Louis, MO, USA]. The 
target sequences and TRC clone numbers were as follows: ER $\alpha$, CTACAGGCCAAATTCAGATAA TRCN0000003300; and ER $\beta$, AGCGATTACGCATCGGGATAT TRCN0000364067. Scrambled control (CCTAAGGTTAAGTCGCCCTCG) shRNA sequences were custom designed.

Lentivirus-ER $\alpha$ or -ER $\beta$ production and infection. Lentivirus-ER $\alpha$ was generated by co-transfecting $293 \mathrm{~T}$ cells (Chinese Academy of Sciences, Shanghai, China) with $4 \mu \mathrm{g}$ ER $\alpha$ shRNA-encoding plasmid, $3 \mu \mathrm{g}$ psPAX2 and $1 \mu \mathrm{g}$ pMD2. Lentivirus-ER $\beta$ was generated by co-transfecting 293T cells with $4 \mu \mathrm{g}$ ER $\beta$ shRNA-encoding plasmid, $3 \mu \mathrm{g}$ psPAX2 and $1 \mu \mathrm{g}$ pMD2 $\mathrm{G}$ plasmids using Lipofectamine 2000 (Invitrogen Life Technologies, Carlsbad, CA, USA). Growth media were exchanged the following day and supernatants were collected every $12 \mathrm{~h}$ over two consecutive days, after $48 \mathrm{~h}$ transfection. Thus, lentivirus-ER $\alpha$ and lentivirus-ER $\beta$ were generated. SKOV3 cells were infected with lentivirus-ER $\alpha$ in the presence of polybrene $(6 \mu \mathrm{g} / \mathrm{ml})$. Media were changed after $12 \mathrm{~h}$ and the cells were selected in $2 \mu \mathrm{g} / \mathrm{ml}$ puromycin two days later. When the infected cells reached $60-70 \%$ confluency, high-titer lentivirus-ER $\beta\left(8 \times 10^{6} \mathrm{IU} / \mathrm{ml}\right)$ with polybrene $(6 \mu \mathrm{g} / \mathrm{ml})$ was added. Media were changed after $12 \mathrm{~h}$ and cells were cultured in $1 \mu \mathrm{g} / \mathrm{ml}$ puromycin for maintenance. After approximately days of incubation, the shRNA ER $\alpha / \beta$ SKOV 3 cell line was obtained with knockdown of ER $\alpha$ and $\beta$ genes.

Cell culture. The human ovarian cancer cell line SKOV3 was obtained from the American Type Culture Collection (Manassas, VA, USA) and maintained in RPMI-1640 (Gibco-BRL, Gaithersburg, MD, USA) supplemented with $10 \%$ fetal bovine serum (FBS; Gibco-BRL). All shRNA-expressing stable cell lines were grown in medium with $1 \mu \mathrm{g} / \mathrm{ml}$ puromycin.

Quantitative polymerase chain reaction. Total RNA was extracted from the targeted and control cells using TRIzol reagent (Invitrogen Life Technologies, Carlsbad, CA, USA) according to the manufacturer's instructions. cDNA was synthesized from $1 \mu \mathrm{g}$ of RNA using the RevertAid First Strand cDNA Synthesis kit (Fermentas, St-Leon-Rot, Germany). The expression levels of ER $\alpha$ and $E R \beta$ were evaluated with an Illumina Eco Real-Time System using a Perfect Real-Time kit (Takara, Shiga, Japan). GAPDH (Kangchen, Shanghai, China) was used as an internal control in each reaction.

Cell invasion assay. Invasion of shRNA ER $\alpha / \beta$ SKOV3 cells through $8-\mu \mathrm{m}$ pores was assessed using a Transwell ${ }^{\circledR}$ Cell Culture chamber (Corning Costar, NY, USA) coated with Matrigel $^{\mathrm{TM}}$ (BD Pharmingen, San Diego, CA, USA). The upper chambers were supplemented with RPMI-1640 media containing $0.5 \%$ FBS while the lower chambers were supplemented with complete media. Cells $(100 \mu \mathrm{l})$ at a density of $1 \times 10^{5}$ cells $/ \mathrm{ml}$ were seeded onto the upper surface of the culture insert with a vehicle [dimethylsulfoxide (DMSO); Sigma-Aldrich], $1 \times 10^{-7} \mathrm{~mol} / 1$ 17- $\beta$ estradiol (Sigma-Aldrich), $1 \times 10^{-5} \mathrm{~mol} / 1 \mathrm{LY} 294002$ (Tocris, Ballwin, MO, USA) or $1 \times 10^{-7} \mathrm{~mol} / 1 \mathrm{1}-\beta$ estradiol plus $1 \times 10^{-5} \mathrm{~mol} / 1 \mathrm{LY} 294002$. After $48 \mathrm{~h}$, the cells on the upper surface of the membrane insert were removed with a cotton swab and the cells that had adhered to the underside of the membrane insert were fixed with methanol and stained with hematoxylin. The number of cells was counted in five random high-power fields using a light microscope. For each experimental condition, the assay was performed in triplicate and the experiment was repeated three times.

Treatment of cells with 17- $\beta$ estradiol and LY294002. shRNA ER $\alpha / \beta$ SKOV3 cells were pretreated with RPMI-1640 media without phenol red containing $10 \%$ active carbon-treated FBS for $48 \mathrm{~h}$. To study the effect of estrogen on AKT and phosphorylated AKT (pAKT) expression, shRNA ER $\alpha / \beta$ SKOV3 cells were treated with serial concentrations $\left(1 \times 10^{-10}, 1 \times 10^{-9}\right.$, $1 \times 10^{-8}$ and $\left.1 \times 10^{-7} \mathrm{~mol} / \mathrm{l}\right)$ of $17-\beta$ estradiol for $1 \mathrm{~h}$ or treated with $1 \times 10^{-7} \mathrm{~mol} / 1 \mathrm{17}-\beta$ estradiol for various periods of time (30, 60 and $120 \mathrm{~min}$ ). To study the combined effect of $17-\beta$ estradiol and LY294002, shRNA ER $\alpha / \beta$ SKOV3 cells were treated with a vehicle (DMSO), $1 \times 10^{-7} \mathrm{~mol} / 1$ 17- $\beta$ estradiol, $1 \times 10^{-5} \mathrm{~mol} / 1 \mathrm{LY} 294002$ or $1 \times 10^{-7} \mathrm{~mol} / 1 \mathrm{17}-\beta$ estradiol plus $1 \times 10^{-5} \mathrm{~mol} / 1 \mathrm{LY} 294002$ for $1 \mathrm{~h}$ to observe the expression of total AKT and pAKT and for $48 \mathrm{~h}$ to observe the expression of E-cadherin and $\alpha$-actinin-4. E-cadherin, $\alpha$-actinin-4, total $\mathrm{AKT}$ and $\mathrm{pAKT}$ protein expression levels were detected using western blot analysis.

Western blot analysis. Treated cells were washed with cold phosphate-buffered saline and lysed in ice-cold cell lysis buffer (radioimmunoprecipitation assay buffer with protease inhibitor cocktail) for cytoplasmic protein extraction or assessed using a Nuclear Extraction kit (Kangchen Bio-tech, Inc., Shanghai, China) for nucleoprotein. The protein extracts were separated by SDS-PAGE and transferred to polyvinylidene difluoride membranes. The membranes were incubated with antibodies against pAKT (1:1,000 dilution; Cell Signaling Technology, Inc., Danvers, MA, USA), total AKT (1:1,000 dilution; Cell Signaling Technology, Inc.), E-cadherin (1:1,000 dilution; Cell Signaling Technology, Inc.) and $\alpha$-actinin-4 (1:500 dilution; Abcam, Cambridge, UK) overnight at $4^{\circ} \mathrm{C}$, rinsed and incubated with the optimal secondary antibody (Kangchen Bio-tech, Inc.). Immunoreactive bands were visualized using the enhanced chemiluminescence detection system (Santa Cruz Biotechnology, Inc., Santa Cruz, CA, USA). GAPDH (1:5,000 dilution; Kangchen) and $\beta$-tubulin (1:500 dilution; Santa Cruz Biotechnology, Inc.) were used as the loading controls for cytoplasmic and nuclear protein, respectively. The semi-quantification of protein levels were measured by Image $\mathrm{J}$ software (National Institutes of Health, Bethesda, MD, USA).

Animal experiments. Female BALB/c mice (Shanghai Cancer Institute, Shanghai, China) used in the present study were treated according to the protocols approved by the Ethics Committee of Fudan University (Shanghai, China). Twenty mice at the age of six weeks were inoculated intraperitoneally with shRNA ER $\alpha / \beta$ SKOV3 cells $\left(1 \times 10^{7}\right.$ cells/mouse in $200 \mu 1$ RPMI-1640). Two weeks after inoculation, the mice were randomly divided into four groups (five mice in each group) to receive either vehicle (DMSO plus phosphate-buffered saline every two days and edible oil every four days), estradiol benzoate (100 mg/kg body weight/every four days, five times), LY294002 (50 mg/kg body weight/every two days, 10 times) or estradiol benzoate plus LY294002, for 20 days. Estradiol benzoate was administered intramusculary and LY294002 was administered 
A
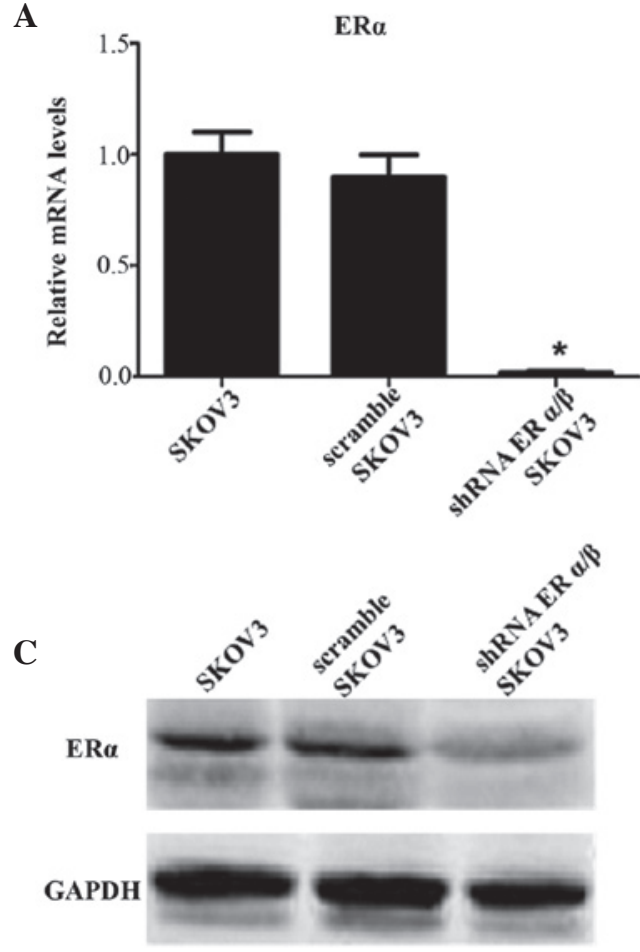

B

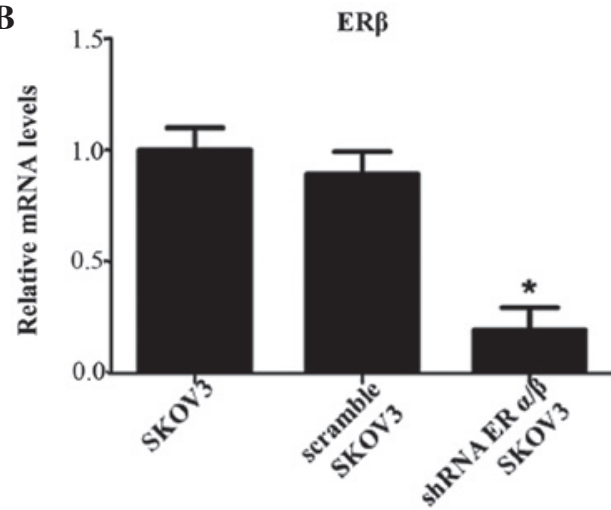

D

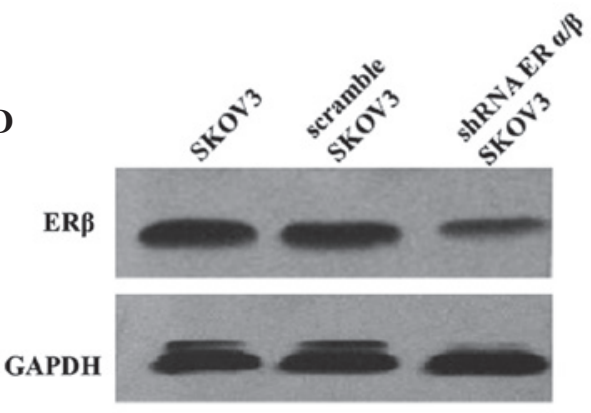

Figure 1. Verification of ER $\alpha$ and ER $\beta$ expression in shRNA ER $\alpha / \beta$ SKOV3 ovarian cancer cells. SKOV3 cells were infected with non-specific shRNA-lentivirus (scramble SKOV3) and shRNA ER $\alpha$ - and $\beta$-lentivirus (shRNA ER $\alpha / \beta$ SKOV3). Unmodified SKOV 3 cells served as a control. (A) ER $\alpha$ and (B) ER $\beta$ mRNA levels in SKOV3, scramble SKOV3 and shRNA ER $\alpha / \beta$ SKOV3 cells were measured by quantitative polymerase chain reaction. (C) ER $\alpha$ and (D) ER $\beta$ protein levels were assessed using western blot analysis. "P<0.05 compared with the control group. shRNA, short hairpin RNA; ER, estrogen receptor.

intraperitoneally. Body weights were measured every four days during treatment. At the end of the experiment, 34 days after tumor cell inoculation, the mice were sacrificed and the tumors were excised and weighed.

Statistical analysis. Data are expressed as the mean \pm standard deviation and analyzed using the $\chi^{2}$ test with SPSS 13.0 software (SPSS, Inc., Chicago, IL, USA). Differences between groups were considered statistically significant at $\mathrm{P}<0.05$.

\section{Results}

Establishment of shRNA ER $\alpha / \beta$ SKOV3 cells. Previous studies conducted by our group showed that estrogen stimulates the migration of ovarian cancer cells via the PI3K/AKT pathway rather than the classical ER pathway (1-3); however, the cell line that was used in these studies expressed low levels of ER, and any potential effects may have been interfered with by these low levels of ER. In order to eliminate the classic effect of estrogen, a cell line with ER $\alpha$ - and ER $\beta$-knockdown was established. The interference efficiency of ER $\alpha$ was $98 \%$ and that of ER $\beta$ was $80.4 \%$ in shRNA ER $\alpha / \beta$ SKOV 3 cells, as shown by quantitative polymerase chain reaction (Fig. 1A and B). shRNA ER $\alpha / \beta$ SKOV3 cells were found to have significantly lower ER $\alpha$ and ER $\beta$ protein expression than SKOV 3 cells, as shown by western blot analysis ( $\mathrm{P}=0.011$ and $\mathrm{P}<0.001$, respectively) (Fig. 1C and D). In the following experiments, only shRNA ER $\alpha / \beta$ SKOV3 cells were used.

Estrogen induces invasion of ER $\alpha / \beta$-knockdown ovarian cancer cells. In the cell invasion assay, the invasion of
shRNA ER $\alpha / \beta$ SKOV3 cells through the porous membrane of the Transwell cell culture chamber was stimulated by $17-\beta$ estradiol and suppressed by LY294002 (Fig. 2A and B). Compared with the control group, the average number of cells crossing the Matrigel-coated membrane in the estrogen group was significantly increased (172 \pm 13 vs. $220 \pm 15$; $\mathrm{P}<0.001)$, while the number was decreased in the LY294002 group (172 \pm 13 vs. $131 \pm 13 ; \mathrm{P}<0.001)$. Compared with the group treated solely with LY294002, the average number of cells crossing the Matrigel-coated membrane in the estrogen plus LY294002 group was increased $(131 \pm 13$ vs. $168 \pm 10$; $\mathrm{P}<0.001)$; however, the number was lower than that in the group treated solely with $17-\beta$ estradiol (168 \pm 10 vs. $220 \pm 15$; $\mathrm{P}<0.001$ ), indicating that LY294002 partly antagonizes the effect of estrogen.

Estrogen activates the PI3K/AKT pathway in ER $\alpha / \beta$-knockdown ovarian cancer cells. In previous studies $(2,3)$, 17- $\beta$ estradiol was demonstrated to activate the PI3K/AKT pathway in ovarian cancer cells. To eliminate the potential classic effect of estrogen via the ER, total AKT and pAKT expression levels were assessed following estrogen treatment in ER $\alpha / \beta$-knockdown ovarian cancer cells. Western blot analysis showed that the pAKT expression significantly increased in a dose-dependent manner and reached a peak following treatment with $17-\beta$ estradiol $1 \times 10^{-7} \mathrm{~mol} / 1(\mathrm{P}<0.001)$ (Fig. 3A and B). 17- $\beta$ estradiol also upregulated pAKT expression, in a time-dependent manner, and this effect reached a peak following treatment for $60 \mathrm{~min}$ at a dose of $1 \times 10^{-7} \mathrm{~mol} / \mathrm{l}$ $(\mathrm{P}<0.001)$ (Fig. 4A and B). 17- $\beta$ estradiol did not affect total AKT expression. 
A

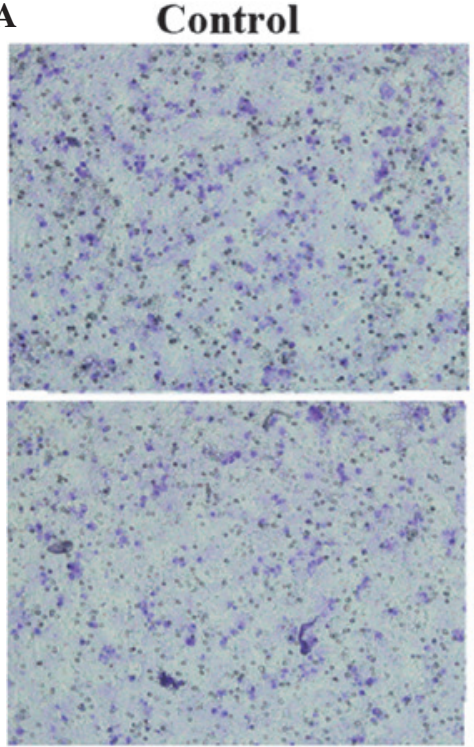

LY294002

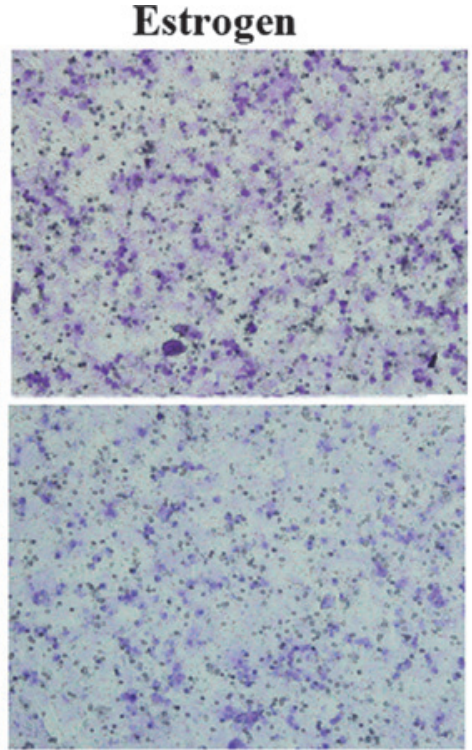

Estrogen +LY294002
B

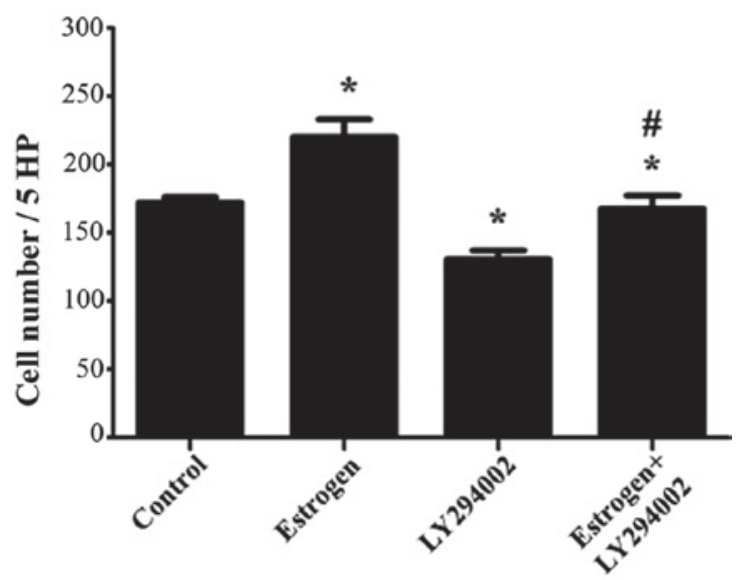

Figure 2. Estrogen stimulated the invasion of shRNA ER $\alpha / \beta$ SKOV3 cells in the cell invasion assay, whereas LY294002 had an inhibitory effect. (A) Effects of estrogen $\left(1 \times 10^{-7} \mathrm{~mol} / \mathrm{l}\right)$ and/or LY294002 $\left(1 \times 10^{-5} \mathrm{~mol} / \mathrm{l}\right)$ on the invasion of shRNA ER $\alpha / \beta$ SKOV3 cells, examined using the Transwell system (magnification, x200; stain, hematoxylin). (B) After 48 h of treatment, the number of successfully invading shRNA ER $\alpha / \beta S K O V 3$ cells was counted. The data are presented as the mean \pm standard deviation. ${ }^{*} \mathrm{P}<0.05$ compared with the control group and ${ }^{\#} \mathrm{P}<0.05$ compared with LY294002 treatment group. shRNA, short hairpin RNA; ER, estrogen receptor; HP, high-power fields.

\section{A}

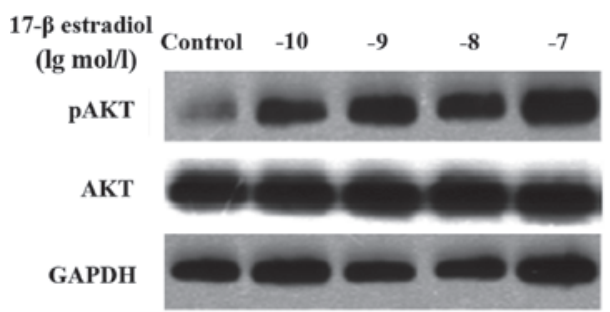

B

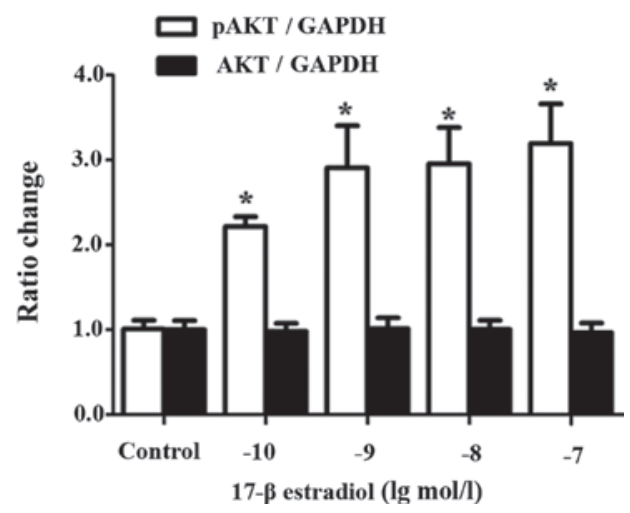

Figure 3. Dose-dependent effect of estrogen on pAKT expression. pAKT, total AKT and GAPDH expression levels in shRNA ER $\alpha / \beta$ SKOV3 cells were detected. (A) Representative western blotting images of lysed cells following $1 \mathrm{~h}$ of incubation with estrogen at various concentrations. (B) Protein levels were semi-quantified using Image J software. "P $<0.05$ compared with the control group. shRNA, short hairpin RNA; ER, estrogen receptor; pAKT, phosphorylated AKT.

Estrogen regulates $E$-cadherin and $\alpha$-actinin- 4 expression in ER $\alpha / \beta$-knockdown ovarian cancer cells and this effect is attenuated by an AKT inhibitor. In order to further confirm the involvement of the PIK3/AKT pathway, shRNA ER $\alpha / \beta$
A

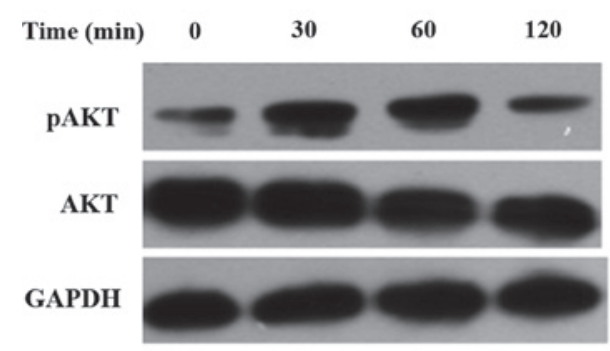

B

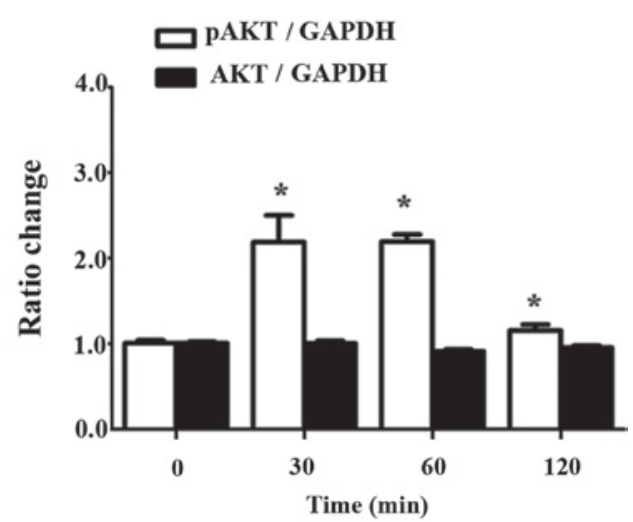

Figure 4. Time-dependent effect of estrogen on pAKT expression. pAKT, total AKT and GAPDH expression levels in shRNA ER $\alpha / \beta$ SKOV3 cells were detected. (A) Representative western blotting images of lysed cells following incubation with estrogen $\left(1 \times 10^{-7} \mathrm{~mol} / \mathrm{l}\right)$ for various periods of time. (B) Protein levels were semi-quantified using Image $\mathrm{J}$ software. ${ }^{\text {" }} \mathrm{P}<0.05$ compared with the control group. shRNA, short hairpin RNA; ER, estrogen receptor; pAKT, phosphorylated AKT.

SKOV3 cells were treated with LY294002 and 17- $\beta$ estradiol, and total AKT and pAKT expression was assessed. Furthermore, the expression of two metastasis-related proteins, 
A
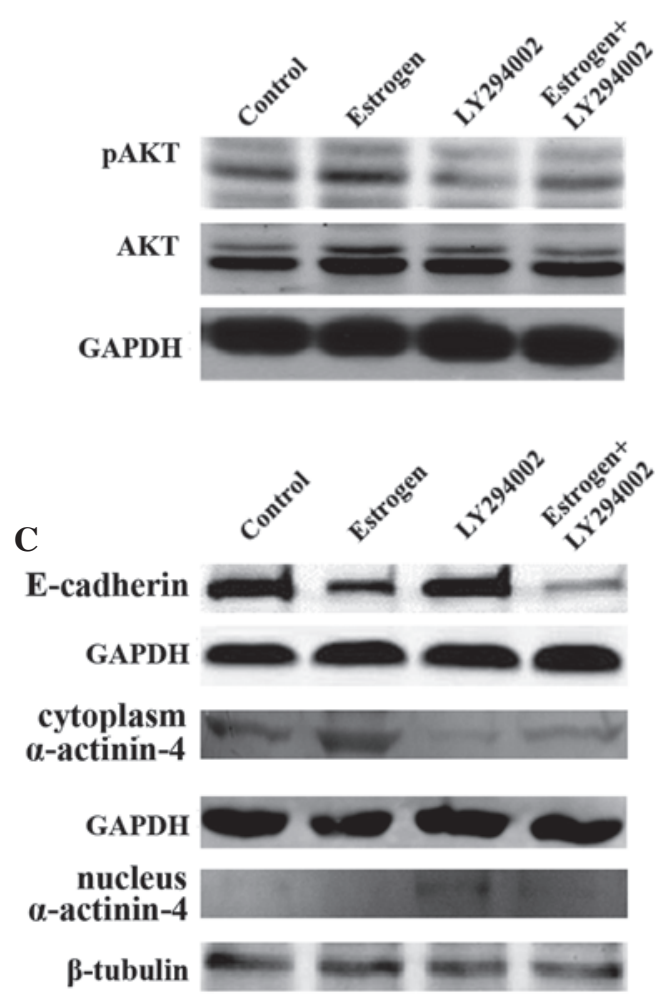

B
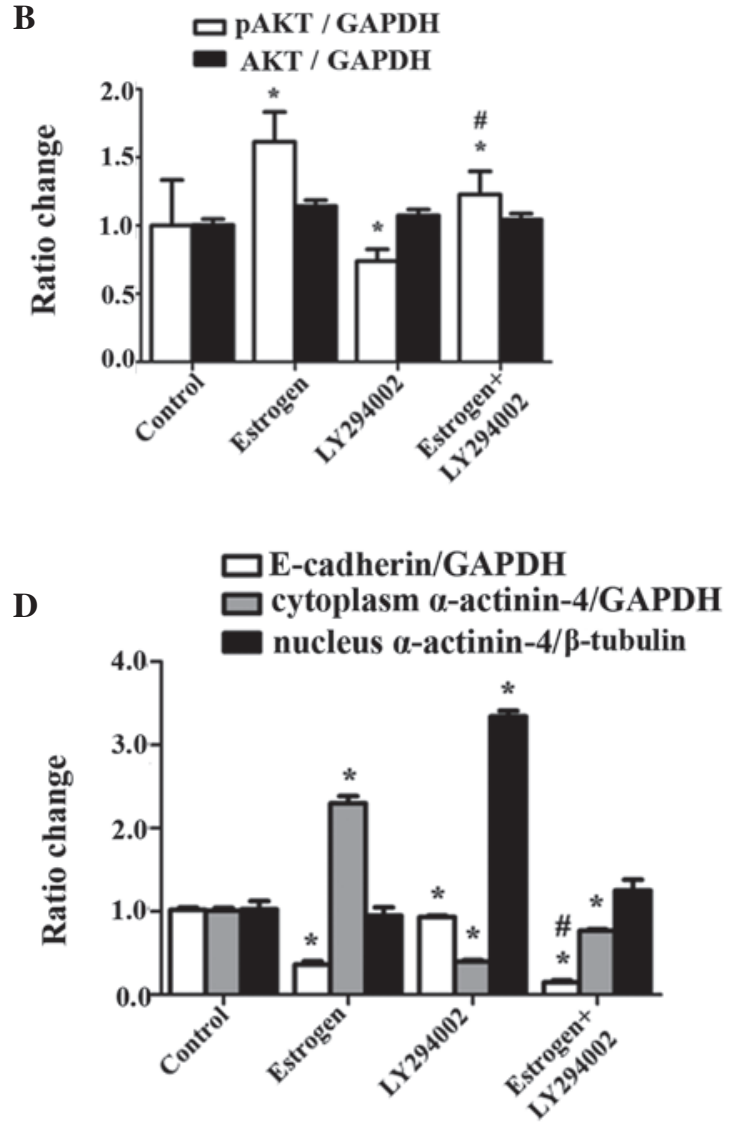

Figure 5. Effect of LY294002 and/or estrogen therapy on shRNA ER $\alpha / \beta$ SKOV3 cells. (A) pAKT and total AKT expression levels were detected using western blot analysis following $1 \mathrm{~h}$ of treatment with estrogen $\left(1 \times 10^{-7} \mathrm{~mol} / \mathrm{l}\right)$, LY294002 (1) $\left.10^{-5} \mathrm{~mol} / \mathrm{l}\right)$ or both. (B) Protein levels were semi-quantified using Image $\mathrm{J}$ software. (C) E-cadherin, cytoplasmic and nuclear $\alpha$-actinin-4 expression levels were detected at $48 \mathrm{~h}$ after treatment with estrogen, LY294002 or both. (D) Protein levels were semi-quantified using Image $\mathbf{J}$ software. For pAKT, AKT, E-cadherin and cytoplasmic $\alpha$-actinin- 4 expression, GAPDH served as a control. For nuclear $\alpha$-actinin-4 expression, $\beta$-tubulin served as control. ${ }^{*} \mathrm{P}<0.05$ compared with the control group and ${ }^{*} \mathrm{P}<0.05$ compared with the LY294002 treatment group. pAKT, phosphorylated AKT; ER. estrogen receptor.

E-cadherin and $\alpha$-actinin- 4 , was assessed to confirm the effect of estrogen on the invasion of shRNA ER $\alpha / \beta$ SKOV 3 cells. As expected, western blot analysis showed that $17-\beta$ estradiol increased pAKT (Fig. 5A and B) and cytoplasmic $\alpha$-actinin-4 (Fig. 5C and D) expression and decreased E-cadherin (Fig. 5C and D) expression as compared with expression in the control group $(\mathrm{P}<0.001)$. The combination of $17-\beta$ estradiol and LY294002 attenuated the function of 17- $\beta$ estradiol alone. Accordingly, following combined treatment of $17-\beta$ estradiol and LY294002, pAKT (Fig. 5A and B) and cytoplasmic $\alpha$-actinin-4 (Fig. 5C and D) expression increased and E-cadherin (Fig. 5C and D) expression decreased as compared with expression in the LY294002 group $(\mathrm{P}<0.001)$. These results further support the hypothesis that estrogen stimulates invasion via directly interacting with the PIK3/AKT pathway and subsequently regulating its downstream targets, E-cadherin and $\alpha$-actinin- 4 .

Estrogen stimulates the growth of ShRNA ER $\alpha / \beta$ SKOV3 xenografts in nude mice, while an AKT inhibitor suppresses the effect of estrogen. The effects of LY294002 and estradiol benzoate, singly and in combination, on the control of shRNA ER $\alpha / \beta$ SKOV3 xenograft growth were examined. shRNA ER $\alpha / \beta$ SKOV3 cells were injected into the abdominal cavity of mice. As it was impossible to measure intraperitoneal tumor spread directly, body weight, which reflects the tumor burden, was measured every four days and the abdominal appearance was observed every day during treatments. Fig. 6A shows representative mice under gross examination. The mice treated solely with estradiol benzoate exhibited significant abdominal swelling. No difference in body weight was found among the four groups (Fig. 6B).

The tumor burden could not be accurately and quantitatively assessed during the treatment period. Therefore, the tumor burden was assessed during the postmortem examination. Autopsy (Fig. 6C) revealed that in the mice treated with estradiol benzoate only, tumors had spread to the surface of the peritoneum, intestines, liver and spleen and into the thoracic cavity. In the mice treated with LY294002 only, tumors were only found on the intestines and liver. All visible tumors were excised and weighed (Fig. 6D). Compared with the control group, the mean tumor burden in the estradiol benzoate group was significantly heavier $(6.39 \pm 0.17$ vs. $11.3 \pm 0.62 \mathrm{~g} ; \mathrm{P}<0.001$; Fig. 6E), while it was markedly lighter in the LY294002 group (6.39 \pm 0.17 vs. $2.44 \pm 0.50$ g; $\mathrm{P}<0.001$; Fig. 6E). Compared with the estradiol benzoate group, the average tumor weight in the estradiol benzoate plus LY294002 group was significantly lighter $(11.3 \pm 0.62$ vs. $9.25 \pm 0.41$ g; $\mathrm{P}<0.001$; Fig. $6 \mathrm{E})$. Consistent with the present in vitro study, LY294002 inhibited the growth of ovarian xenograft tumors induced by estrogen. 
A

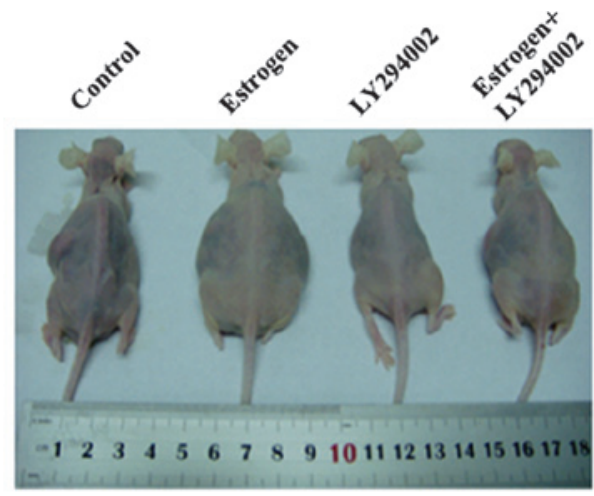

C

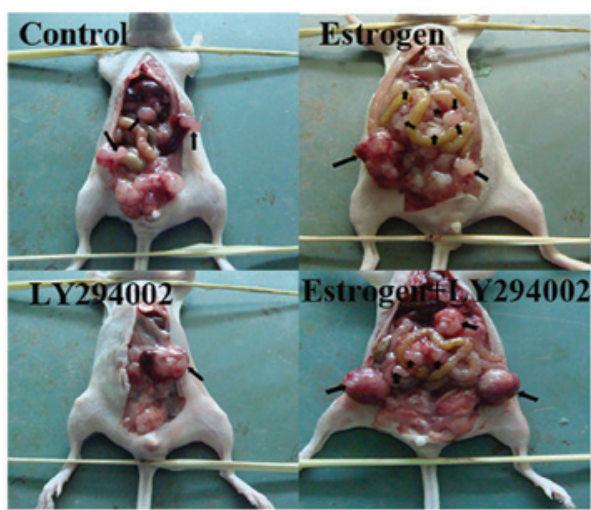

D

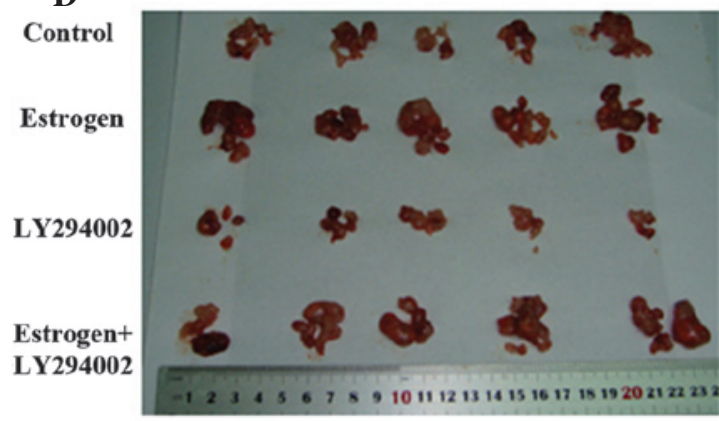

B

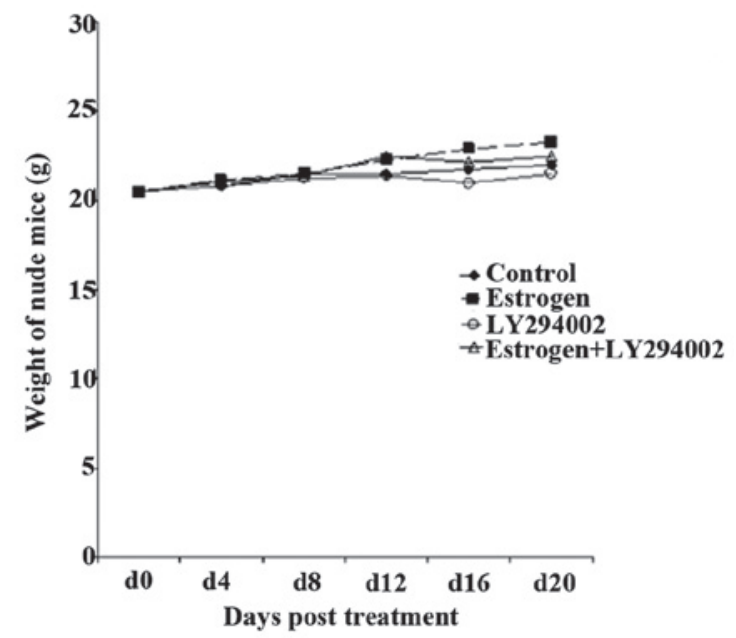

E

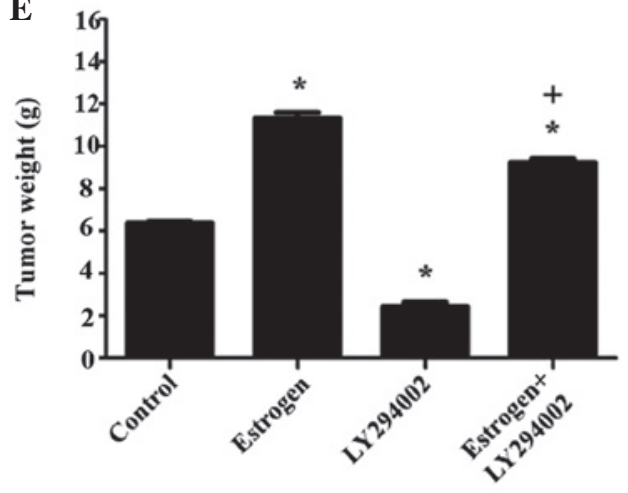

Figure 6. Effects of LY294002 and/or estradiol benzoate therapy in mice inoculated with shRNA ER $\alpha / \beta$ SKOV3 cells. (A) General appearance of mice bearing tumors at the study end-point. (B) Weight curve of mice of four groups (control, estradiol benzoate, LY294002 and estradiol benzoate plus LY294002). (C) Gross examination of peritoneal cavities of mice at necropsy. Arrows indicate tumors. (D) Xenografts of mice at the study end-point. (E) Tumor weight at the study end-point. Values represent the mean \pm standard deviation of $n=5$. ${ }^{*} \mathrm{P}<0.05$ compared with the control group and ${ }^{+} \mathrm{P}<0.05$ compared with the estrogen group. ER, estrogen receptor.

\section{Discussion}

The effect and mechanisms underlying the action of estrogen on metastasis in ovarian cancer remains unclear and controversial. The findings of the present study have extended the understanding of the involvement of the PI3K/AKT pathway in the estrogen-induced invasion and regulation of metastasis-associated proteins in an ER $\alpha / \beta$-knockdown ovarian cancer cell line. It was demonstrated that estrogen could activate the PI3K/AKT pathway, decrease E-cadherin levels, upregulate $\alpha$-actinin-4 levels and promote invasion in ovarian cancer cells.

Previous studies have associated estrogen with ovarian cancer metastasis $(19,20)$. Little is known about how estrogen promotes cell metastasis. Estrogen has been traditionally considered to function only by binding to nuclear ER. Previous studies by our group confirmed that the PI3K/AKT pathway was involved in the regulation of cell metastasis stimulated by estrogen in ovarian cancer cells $(2,3)$.

The invasion of cancer cells to a site of potential metastasis depends on a series of complex biological steps, regulated by multiple genes (21). In the present study, using a cell line with ER $\alpha$ - and ER $\beta$-knockdown, the potential role of the ER pathway involved in the effect of estrogen was eliminated. As expected, estrogen was able to stimulate the invasion of shRNA ER $\alpha / \beta$ SKOV3 cells, while the effect was partially suppressed by AKT inhibitors. Consistent with the in vitro study, estrogen caused a marked spread of shRNA ER $\alpha / \beta$ SKOV3 cells within the peritoneal cavity of the mice and the greatest tumor burden; however, these effects were inhibited by LY294002. Additionally, in vitro studies revealed that estrogen interacted with the PI3K/AKT pathway and regulated its downstream proteins, E-cadherin and $\alpha$-actinin- 4 . 
The PI3K/AKT cell-signaling pathway is involved in cell migration and invasion (22-24). AKT has been shown to be amplified or overexpressed in ovarian cancer, indicating that it has a role in ovarian cancer metastasis (25-27). Consistent with these observations, a rapid increase in AKT phosphorylation upon estrogen treatment was found in shRNA ER $\alpha / \beta$ SKOV3 cells (Figs. 3 and 4). Accordingly, a decrease in E-cadherin and an increase in cytoplasmic $\alpha$-actinin- 4 expression levels were observed under estrogen treatment. Thus, the importance of the PI3K/AKT pathway in the regulation of E-cadherin and $\alpha$-actinin- 4 in ovarian cancer cells by estrogen was further confirmed.

Given the important role of the PI3K/AKT pathway in estrogen-induced metastasis, a PI3K/AKT inhibitor was further used to investigate whether the effect of estrogen was able to be antagonized. The present study revealed that LY294002, a PI3K inhibitor, markedly inhibited the spread of ovarian cancer in athymic mice inoculated with shRNA ER $\alpha / \beta$ SKOV3 cells in vivo and suppressed the invasion of shRNA ER $\alpha / \beta$ SKOV 3 cells in vitro. Following treatment with a combination of LY294002 plus 17- $\beta$ estradiol, the expression of pAKT was suppressed compared with that following treatment with estrogen alone. By contrast, treatment with estrogen alone increased the expression of cytoplasmic $\alpha$-actinin-4 relative to that in the LY294002 plus 17- $\beta$ estradiol group. These results further support the association between the PIK3/AKT pathway and the effect of estrogen on cell metastasis.

The present study demonstrated that $17-\beta$ estradiol was able to enhance invasive capability by regulating E-cadherin and $\alpha$-actinin- 4 through activating the PIK3/AKT pathway in ER $\alpha / \beta$-knockdown ovarian cancer cells, which is a supplement to our preliminary studies. However, in the present study, although the ER expression was largely knocked down, the remaining low level of ER in the shRNA ER $\alpha / \beta$ SKOV3 cells may still have played a biological function. The interaction between the PI3K/AKT pathway and the classical ER pathway remains to be clarified.

In conclusion, estrogen promotes the invasion of ovarian cancer cells via the activation of the PI3K/AKT pathway and subsequent E-cadherin downregulation and $\alpha$-actinin-4 upregulation; this effect is ER-independent. Inhibiting the PI3K/AKT pathway may be a useful treatment for ovarian carcinoma.

\section{Acknowledgements}

The present study was supported by the National Natural Science Foundation of China (no. 81072131).

\section{References}

1. Ding JX, Feng YJ, Yao LQ, Yu M, Jin HY and Yin LH: The reinforcement of invasion in epithelial ovarian cancer cells by 17 beta-estradiol is associated with upregulation of Snail. Gynecol Oncol 103: 623-630, 2006.

2. Hua K, Feng W, Cao Q, Zhou X, Lu X and Feng Y: Estrogen and progestin regulate metastasis through the PI3K/AKT pathway in human ovarian cancer. Int J Oncol 33: 959-967, 2008.

3. Hua K, Din J, Cao Q, Feng W, Zhang Y, Yao L, Huang Y, Zhao Y and Feng Y: Estrogen and progestin regulate HIF-1alpha expression in ovarian cancer cell lines via the activation of Akt signaling transduction pathway. Oncol Rep 21: 893-898, 2009.
4. Kong L, Schäfer G, Bu H, Zhang Y, Zhang Y and Klocker H: Lamin A/C protein is overexpressed in tissue-invading prostate cancer and promotes prostate cancer cell growth, migration and invasion through the PI3K/AKT/PTEN pathway. Carcinogenesis 33: 751-759, 2012.

5. Riggio M, Polo ML, Blaustein M, Colman-Lerner A, Lüthy I, Lanari C and Novaro V: PI3K/AKT pathway regulates phosphorylation of steroid receptors, hormone independence and tumor differentiation in breast cancer. Carcinogenesis 33: 509-518, 2012.

6. Huang XF and Chen JZ: Obesity, the PI3K/AKT signal pathway and colon cancer. Obes Rev 10: 610-616, 2009.

7. Cantley LC, Auger KR, Carpenter C, Duckworth B, Graziani A, Kapeller R and Soltoff S: Oncogenes and signal transduction. Cell 64: 281-302, 1991.

8. Cantley LC and Neel BG: New insights into tumor suppression: PTEN suppresses tumor formation by restraining the phosphoinositide 3-kinase/AKT pathway. Proc Natl Acad Sci USA 96: 4240-4245, 1999.

9. Yip WK and Seow HF: Activation of phosphatidylinositol 3-kinase/AKT signaling by EGF downregulates membranous E-cadherin and $\beta$-catenin and enhances invasion in nasopharyngeal carcinoma cells. Cancer Lett 318: 162-172, 2012.

10. Wang Y, Sheng Q, Spillman MA, Behbakht K and Gu H: Gab2 regulates the migratory behaviors and E-cadherin expression via activation of the PI3K pathway in ovarian cancer cells. Oncogene 31: 2512-2520, 2012.

11. Shibasaki F, Fukami K, Fukui Y and Takenawa T: Phosphatidylinositol 3-kinase binds to alpha-actinin through the p85 subunit. Biochem J 302: 551-557, 1994.

12. Ding Z, Liang J, Lu Y, Yu Q, Songyang Z, Lin SY and Mills GB: A retrovirus-based protein complementation assay screen reveals functional AKT1-binding partners. Proc Natl Acad Sci USA 103: 15014-15019, 2006.

13. Koay MH, Crook M and Stewart CJ: Cyclin D1, E-cadherin and beta-catenin expression in FIGO Stage IA cervical squamous carcinoma: diagnostic value and evidence for epithelial-mesenchymal transition. Histopathology 61: 1125-1133, 2012.

14. Xiong H, Hong J, Du W, Lin YW, Ren LL, Wang YC, Su WY, Wang JL, Cui Y, Wang ZH and Fang JY: Roles of STAT3 and ZEB1 proteins in E-cadherin down-regulation and human colorectal cancer epithelial-mesenchymal transition. J Biol Chem 287: 5819-5832, 2012.

15. Lombaerts M, van Wezel T,Philippo K, Dierssen JW,Zimmerman RM, Oosting J, van Eijk R, Eilers PH, van de Water B, Cornelisse CJ and Cleton-Jansen AM: E-cadherin transcriptional downregulation by promoter methylation but not mutation is related to epithelial-to-mesenchymal transition in breast cancer cell lines. Br J Cancer 94: 661-671, 2006.

16. Gravdal K, Halvorsen OJ, Haukaas SA and Akslen LA: A switch from $\mathrm{E}$-cadherin to $\mathrm{N}$-cadherin expression indicates epithelial to mesenchymal transition and is of strong and independent importance for the progress of prostate cancer. Clin Cancer Res 13: 7003-7011, 2007.

17. Lau MT, Klausen C and Leung PC: E-cadherin inhibits tumor cell growth by suppressing PI3K/AKT signaling via $\beta$-catenin-Egrl-mediated PTEN expression. Oncogene 30: 2753-2766, 2011.

18. Cheng JC, Auersperg N and Leung PC: Inhibition of p53 induces invasion of serous borderline ovarian tumor cells by accentuating PI3K/Akt-mediated suppression of E-cadherin. Oncogene 30: 1020-1031, 2011.

19. Pearce ST and Jordan VC: The biological role of estrogen receptors alpha and beta in cancer. Crit Rev Oncol Hematol 50: 3-22, 2004.

20. Park SH, Cheung LW, Wong AS and Leung PC: Estrogen regulates Snail and Slug in the down-regulation of E-cadherin and induces metastatic potential of ovarian cancer cells through estrogen receptor alpha. Mol Endocrinol 22: 2085-2098, 2008.

21. Kohn EC and Liotta LA: Molecular insights into cancer invasion: strategies for prevention and intervention. Cancer Res 55: $1856-1862,1995$.

22. Brustmann H and Naudé S: Expression of nm23 in normal, hyperplastic and neoplastic endometrial tissues. Pathol Res Pract 195: 829-834, 1999.

23. Chen XF, Zhang HT, Qi QY, Sun MM and Tao LY: Expression of E-cadherin and $\mathrm{nm} 23$ is associated with the clinicopathological factors of human non-small cell lung cancer in China. Lung Cancer 48: 69-76, 2005. 
24. Ohta S, Lai EW, Pang AL, Brouwers FM, Chan WY, Eisenhofer G, de Krijger R, Ksinantova L, Breza J, Blazicek P, Kvetnansky R, Wesley RA and Pacak K: Downregulation of metastasis suppressor genes in malignant pheochromocytoma. Int J Cancer 114: 139-143, 2005.

25. Bellacosa A, de Feo D, Godwin AK, Bell DW, Cheng JQ, Altomare DA, Wan M, Dubeau L, Scambia G, Masciullo V, Ferrandina G, Benedetti Panici P, Mancuso S, Neri G and Testa JR: Molecular alterations of the AKT2 oncogene in ovarian and breast carcinomas. Int J Cancer 64: 280-285, 1995.
26. Yuan ZQ, Sun M,Feldman RI, Wang G, Ma X, Jiang C, Coppola D, Nicosia SV and Cheng JQ: Frequent activation of AKT2 and induction of apoptosis by inhibition of phosphoinositide-3-OH kinase/Akt pathway in human ovarian cancer. Oncogene 19: 2324-2330, 2000

27. Altomare DA, Wang HQ, Skele KL, De Rienzo A, Klein-Szanto AJ, Godwin AK and Testa JR: AKT and mTOR phosphorylation is frequently detected in ovarian cancer and can be targeted to disrupt ovarian tumor cell growth. Oncogene 23: 5853-5857, 2004 